\title{
A anatomia estrutural e funcional da esquizofrenia: achados de neuropatologia e neuroimagem
}

\author{
Geraldo Busatto Filho
}

Departamento de Psiquiatria, FMUSP

A existência de alterações cerebrais subjacentes aos sintomas da esquizofrenia já era admitida desde as propostas de classificação clássicas para esse transtorno. Entre as várias estratégias de pesquisa biológica utilizadas nas últimas décadas, as técnicas neuropatológicas e de neuroimagem estão entre as que mais têm contribuído para o conhecimento dos mecanismos cerebrais alterados na esquizofrenia.

\section{Neuropatologia}

Desde a década de 80 , estudos morfométicos quantitativos post mortem têm mostrado anormalidades nos cérebros de alguns pacientes esquizofrênicos, incluindo diminuições globais de volume/peso e reduções localizadas em áreas temporais e frontais. ${ }^{1}$ Além disso, há achados histológicos de anormalidades de citoarquitetura nessas áreas, incluindo alterações no número, tamanho e distribuição dos neurônios em camadas. ${ }^{2}$ Um aspecto importante dos estudos histopatológicos é a ausência de um excesso de células gliais, indicando que as alterações observadas não são decorrentes de processos degenerativos.

Estudos neuropatológicos têm investigado também aspectos neuroquímicos na esquizofrenia, classicamente por meio do uso de radioligantes que marcam subtipos específicos de receptores cerebrais. Dada a relevância das hipóteses que pressupõem alterações de neurotransmissão dopaminérgica na doença, anormalidades de receptores dopaminérgicos têm sido intensamente investigadas. No entanto, os resultados nessa área são conflitantes, possivelmente pelo fator de confusão introduzido pelo uso de drogas antipsicóticas em vida. ${ }^{3}$ Recentemente, estudos neuroquímicos mais sofisticados têm usado a biologia molecular para investigar alterações na expressão de genes e proteínas específicos em cérebros de pacientes esquizofrênicos. Nessa área, há achados consistentes envolvendo outros neurotransmissores relevantes para a esquizofrenia, incluindo diminuições na expressão de genes para receptores de glutamato e ácido gama-aminobutírico (GABA). ${ }^{4}$

\section{Neuroimagem estrutural}

Já na década de 70, estudos com tomografia computadorizada (TC) de crânio, comparando pacientes esquizofrênicos e voluntários normais, mostravam aumentos significativos de ventrículos laterais em aproximadamente $20-25 \%$ dos pacientes e alargamento de sulcos corticais em $10-15 \%$ dos casos. ${ }^{5} \mathrm{~A}$ partir da década de 80, passou a ser possível realizar tais estu- dos com a técnica de ressonância magnética (RM), que propicia maior resolução espacial, melhor diferenciação entre substância cinzenta e branca e dispensa o uso de radiação ionizante. Estudos de RM têm replicado os achados de dilatação ventricular e alargamento de sulcos corticais na esquizofrenia, além de identificar diminuições volumétricas de substância cinzenta no cérebro de pacientes esquizofrênicos. Essas alterações se mostram difusas em alguns estudos ${ }^{6} \mathrm{e}$, em outros, localizadas para porções de córtex temporal e pré-frontal, gânglios da base e tálamo. ${ }^{7} \mathrm{O}$ campo das pesquisas de RM na esquizofrenia continua em expansão graças a novos desenvolvimentos, tais como métodos automáticos para segmentação de imagens (Figura 1) e comparações estatísticas de volumes cerebrais regionais entre grupos de pacientes e voluntários normais.
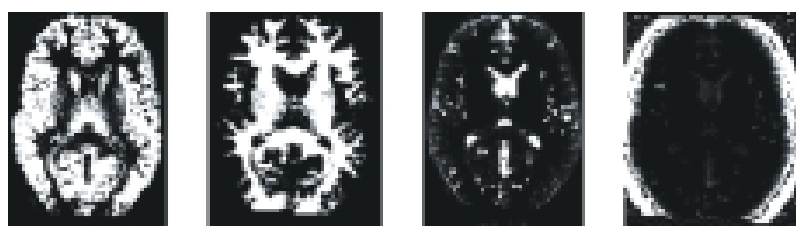

Figura 1 - Imagem cerebral (corte transversal) obtida em um voluntário normal pela técnica de ressonância magnética estrutural.

Imagens pesadas em T1 foram segmentadas em 4 compartimentos, representando respectivamente (da esquerda para a direita): substância cinzenta, substância branca, líquido céfalo-raquidiano e crânio/escalpo

\section{Neuroimagem funcional}

As técnicas funcionais, por fornecerem imagens dinâmicas do metabolismo cerebral regional, são as mais utilizadas para estabelecer relações entre a intensidade de sintomas mentais e as alterações do funcionamento cerebral. Os métodos mais usados são as tomografias por emissão de pósitron e fóton único (PET e SPECT), que permitem a construção de mapas tridimensionais da atividade cerebral a partir da detecção de raios-gama emitidos por traçadores marcados com isótopos radioativos. Os traçadores mais usados, por via venosa, são os que medem o fluxo sanguíneo cerebral regional (Figura 2A) ou o metabolismo de glicose, ambos representando correlatos fiéis do funcionamento cerebral regional. 


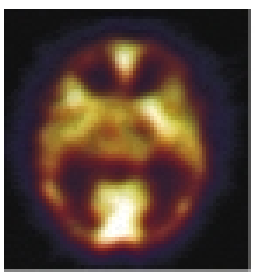

(A)

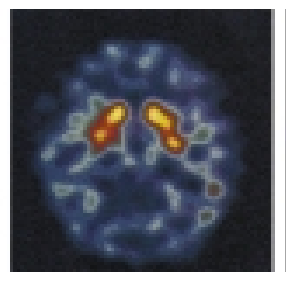

(B)

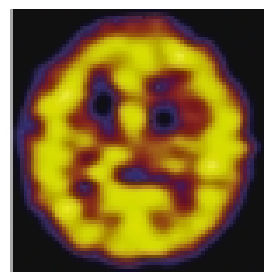

(C)
Figura 2 - Imagens de SPECT cerebral (cortes transversais) obtidas em voluntários normais

As imagens mostram: (A) o fluxo sanguíneo cerebral regional, (B) a distribuição de receptores dopaminérgicos D2 e (C) a distribuição de receptores serotoninérgicos $5-\mathrm{HT} 2$.

Há grande variabilidade de resultados nos estudos de PET e SPECTcomparando pacientes esquizofrênicos e voluntários normais em repouso. $\mathrm{O}$ achado mais comum é o de diminuição da atividade metabólica no córtex pré-frontal (hipofrontalidade), mais freqüentemente em pacientes com sintomas negativos intensos. ${ }^{8}$ Já sintomas positivos têm sido relacionados à hiperatividade em circuitos envolvendo áreas temporolímbicas, córtex pré-frontal e gânglios da base. ${ }^{9}$ Técnicas de PET e SPECT têm sido também utilizadas para obter imagens durante tarefas de ativação mental. São clássicos, nessa linha, trabalhos mostrando hipofrontalidade em pacientes esquizofrênicos durante tarefas que demandam flexibilidade mental. ${ }^{10}$ Os estudos de ativação com tarefas neuropsicológicas vêm se sofisticando progressivamente. Eles têm permitido o mapeamento de áreas corticais múltiplas que se mostram dissonantes em pacientes esquizofrênicos e também têm indicado como a integração do funcionamento entre essas áreas está prejudicada durante a execução das tarefas. ${ }^{11}$ Além disso, novos paradigmas têm sido desenhados especificamente para detectar anormalidades de ativação cortical relacionadas a aspectos peculiares da sintomatologia esquizofrênica, tais como experiências de passividade e alucinações auditivas de primeira ordem de Schneider. ${ }^{12}$

\section{Novas frentes: ressonância magnética funcional}

Com o desenvolvimento da RM funcional (RMf), é possível utilizar os princípios da RM para obter informações funcionais dinâmicas pela detecção das variações sutis no grau de oxigenação da hemoglobina ocorridas quando há mudanças na atividade cerebral em resposta à estimulação mental. São utilizadas bobinas "eco-planares", que produzem centenas de imagens seqüenciais do cérebro inteiro em segundos, possibilitando a detecção de mudanças transitórias de atividade funcional em múltiplas áreas cerebrais durante a execução de tarefas mentais. Já há estudos preliminares com essa técnica demonstrando, por exemplo, que pacientes esquizofrênicos com sintomas alucinatórios tendem a apresentar ativação atenuada do córtex temporal durante a audição de material verbal em comparação com voluntários normais, ${ }^{13}$ com reversão relativa dessa anormalidade após o tratamento. Esses resultados sugerem que os mesmos circuitos corticais ativados para a percepção auditiva normal são engajados durante a atividade alucinatória na es- quizofrenia. Há também estudos de RMf na esquizofrenia replicando o achado de hipofrontalidade durante tarefas cognitivas, ${ }^{14}$ e outros mostrando anormalidades em áreas límbicas durante tarefas de indução de tristeza. ${ }^{15}$

\section{Imagens neuroquímicas na esquizofrenia}

Voltando às técnicas de PET/SPECT, as mesmas podem também ser usadas para obter imagens mostrando a distribuição in vivo de subtipos de neurorreceptores e terminais sinápticos específicos, após a administração venosa de radioligantes (Figura 2B e 2C). Diversos pesquisadores têm usado esses métodos para comparar a distribuição de receptores dopaminérgicos $\mathrm{D}_{2}$ em pacientes esquizofrênicos não-medicados e voluntários normais. ${ }^{3,16}$ Esses estudos não mostram anormalidades grosseiras em esquizofrênicos, mas há achados sutis de assimetrias de receptores $\mathrm{D}_{2}$ nos gânglios da base, além de diminuições robustas na captação do radioligante em sítios $\mathrm{D}_{2}$ após a administração de anfetamina (sugerindo liberação excessiva de dopamina endógena em pacientes esquizofrênicos ${ }^{16}$ ). Mais recentemente, vêm sendo também desenvolvidos radioligantes que marcam receptores para outros neurotransmissores, como serotonina - 5- $\mathrm{HT}_{2}-$ (Figura 2C), glutamato e Gaba. Esses ligantes começam agora a ser usados com PET/SPECT para testar outras hipóteses neuroquímicas para a esquizofrenia. ${ }^{17}$

As técnicas de imagem neuroquímica têm sido usadas também para elucidar o mecanismo de ação de antipsicóticos. Sabese, por estudos com PET e SPECT, que o bloqueio dopaminérgico $\mathrm{D}_{2}$ de até cerca de $70 \%$ é suficiente para pacientes que responderão ao tratamento neuroléptico convencional, enquanto níveis acima desse limiar levam ao surgimento desnecessário de efeitos extrapiramidais.,16 Demonstrou-se também que pacientes refratários que acabam por responder ao antipsicótico atípico clozapina apresentam bloqueio $\mathrm{D}_{2}$ não mais que moderado sob o uso dessa droga, indicando que mecanismos adicionais, não-dopaminérgicos de ação da mesma, devem ser importantes para sua eficácia. ${ }^{16} \mathrm{Com}$ a consolidação dessa técnica de neuroimagem, inúmeros outros novos antipsicóticos têm tido seus padrões de bloqueio de receptores $\mathrm{D}_{2}$ e $5-\mathrm{HT}_{2}$ documentados por meio de estudos de PET e SPECT. ${ }^{16,18}$

\section{Neuroimagem na esquizofrenia: há aplicações clínicas?}

Os achados de neuroimagem acima resultam de comparações estatísticas de valores médios entre grupos de pacientes esquizofrênicos e controles normais. Nesses estudos, apenas uma parcela dos pacientes investigados apresenta valores nitidamente fora dos padrões normais (mesmo no caso dos achados mais clássicos, como os de dilatação ventricular ou de hipofrontalidade). Além disso, os achados de neuroimagem são pouco específicos para a esquizofrenia, surgindo também em transtornos do humor e diversos outros. Essas limitações de sensitividade e especificidade restringem as aplicações diagnósticas das técnicas de neuroimagem na esquizofrenia. Esses exames se mostram clinicamente relevantes somente nos casos em que sintomas psicóticos constituem manifestação clínica de condições médicas insuspeitadas, como, por exemplo, neoplasias cerebrais ou hematomas subdurais. Essas situações, ainda que 
bastante raras, justificam a inclusão da TC ou da RM de crânio na avaliação inicial de pacientes em primeiro episódio psicótico, sobretudo quando há sintomas incomuns, e/ou a idade de início é atípica, e/ou não há história familiar de transtornos psicóticos.

\section{Implicações etiológicas dos achados de pesquisa}

Se as aplicações clínicas das técnicas neurorradiológicas na esquizofrenia são limitadas, por outro lado é notável o peso dado aos achados de neuropatologia e neuroimagem nas formulações contemporâneas sobre a etiologia da doença. Hipóteses mais antigas de que a esquizofrenia resultaria direta e unicamente de um processo de degeneração cerebral são hoje pouco consideradas, fundamentalmente pela ausência de gliose nas análises histológicas mencionadas acima. A partir da década de 80, ganhou força a visão alternativa de que a esquizofrenia poderia resultar de alterações do neurodesenvolvimento, com fatores causais atuantes já em vida intra-uterina ou em estágios precoces pós-nascimento. ${ }^{19}$ Achados epidemiológicos e clínicos dão suporte a essa hipótese, ${ }^{19}$ que é reforçada também pelas anormalidades de citoarquitetura citadas no presente artigo, algumas das quais são características de eta- pas de migração neuronal ocorridas ainda durante a gestação. ${ }^{2}$

Por outro lado, os achados de RM estrutural na esquizofrenia, combinando alargamento de sulcos corticais, redução de substância cinzenta e dilatação ventricular, sugerem perda excessiva de volume cerebral após maturação completa. ${ }^{19}$ Além disso, estudos com medidas seriadas de RM estrutural mostram progressão das alterações cerebrais estruturais com a evolução da esquizofrenia. ${ }^{20}$ Tentando conciliar todos esses achados, modelos teóricos recentes mantêm a hipótese da esquizofrenia como um transtorno do neurodesenvolvimento, mas propõem também a existência de um componente progressivo de redução volumétrica cerebral com a evolução da doença, talvez resultante de anormalidades em processos de morte celular programada (apoptose). ${ }^{18}$ A consolidação desses modelos unificadores, por intermédio de novas pesquisas, poderá guiar o desenvolvimento de estratégias preventivas para a esquizofrenia, assim como reforçar a importância de intervenções precoces e eficazes que possam retardar a progressão da doença.

Fonte de financiamento: Fapesp (processo nº 95/9446-1).

\section{Referências}

1. Stevens JR. Neuropathologies of schizophrenia. In: Gattaz WF, Häfner H, editors. Search for the causes of schizophrenia: balance of the century. Darmstadt: Steinkopff; 1999. p.221-34.

2. Arnold SE, Ruscheinsky DD, Han LY. Further evidence of abnormal cytoarchitecture of the entorhinal cortex in schizophrenia using spatial point pattern analyses. Biol Psychiatry 1997;15:639-47.

3. Farde L. Brain imaging of schizophrenia - the dopamine hypothesis. Schizophr Res 1997;28:157-62.

4. Akbarian S, Sucher NJ, Bradley D, Tafazzoli A, Trinh D, Hetrick WP et al. Selective alterations in gene expression for NMDA receptor subunits in prefrontal cortex of schizophrenics. J Neurosci 1996;16:19-30.

5. Lewis SW. Computerised tomography in schizophrenia - 15 years on. Br J Psychiatry 1990;(Suppl 9):16-24.

6. Gur RE, Turetsky BI, Bilker WB, Gur RC. Reduced gray matter volume in schizophrenia. Arch Gen Psychiatry 1999;56:905-11.

7. Seidman LJ, Faraone SV, Goldstein JM, Goodman JM, Kremen WS, Toomey $\mathrm{R}$ et al. Thalamic and amygdala-hippocampal volume reductions in first-degree relatives of patients with schizophrenia: an MRI-based morphometric analysis. Biol Psychiatry 1999;46:941-54.

8. Schroder J, Buchsbaum MS, Siegel BV, Geider FJ, Lohr J, Tang C et al. Cerebral metabolic activity correlates of subsyndromes in chronic schizophrenia. Schizophr Res 1996;19:41-53.

9. Silbersweig DA, Stern E, Frith C, Cahill C, Holmes A, Grootoonk S et al. A functional neuroanatomy of hallucinations in schizophrenia. Nature 1995;378:176-9.

10.Andreasen NC, Rezai K, Alliger R, Swayze VW 2d, Flaum M, Kirchner $\mathrm{P}$ et al. Hypofrontality in neuroleptic-naive patients and in patients with chronic schizophrenia. Assessment with xenon 133 single-photon emission computed tomography and the Tower of London. Arch Gen Psychiatry 1992;49:943-58.

11.Fletcher P, McKenna PJ, Friston KJ, Frith CD, Dolan RJ. Abnormal cingulate modulation of fronto-temporal connectivity in schizophrenia. Neuroimage 1999;9:337-42.
12.McGuire PK, Silbersweig DA, Wright I, Murray RM, Frackowiak RS, Frith CD. The neural correlates of inner speech and auditory verbal imagery in schizophrenia: relationship to auditory verbal hallucinations. Br J Psychiatry 1996;169:148-59.

13. Woodruff PW, Wright IC, Bullmore ET, Brammer M, Howard RJ, Williams SC et al. Auditory hallucinations and the temporal cortical response to speech in schizophrenia: a functional magnetic resonance imaging study. Am J Psychiatry 1997; 154:1676-82.

14.Curtis VA, Bullmore ET, Brammer MJ, Wright IC, Williams SC, Morris RG et al. Attenuated frontal activation during a verbal fluency task in patients with schizophrenia. Am J Psychiatry 1998; 155:1056-63.

15. Schneider F, Weiss U, Kessler C, Salloum JB, Posse S, Grodd W et al. Differential amygdala activation in schizophrenia during sadness. Schizophr Res 1998;34:133-42.

16.Bigliani V, Pilowsky LS. The in vivo neurochemistry of schizophrenia. Br J Psychiatry 1999;74Supl 38:23-33.

17.Busatto GF, Pilowsky LS, Costa DC, Ell PJ, David AS, Lucey JV et al. Correlation between reduced in vivo benzodiazepine receptor binding and severity of psychotic symptoms in schizophrenia. Am J Psychiatry 1997;154:56-63.

18. Busatto GF, Pilowsky LS, Costa DC, Ell PJ, Verhoeff NP, Kerwin RW. Dopamine D2 receptor blockade in vivo with the novel antipsychotics risperidone and remoxipride - an 123I-IBZM single photon emission tomography (SPET) study. Psychopharmacology 1995; 117:55-61.

19.Woods BT. Is schizophrenia a progressive neurodevelopmental disorder? Toward a unitary pathogenetic mechanism. Am J Psychiatry 1998;155:1661-70.

20.Rapoport JL, Giedd JN, Blumenthal J, Hamburger S, Jeffries N, Fernandez T et al. Progressive cortical change during adolescence in childhood-onset schizophrenia. A longitudinal magnetic resonance imaging study. Arch Gen Psychiatry 1999;56:649-54.

Correspondência: Geraldo Busatto Filho

Departamento de Psiquiatria da FMUSP - Rua Ovídio Pires Campos, s/n

CEP 05403-010, São Paulo, SP - Tel./ fax: (0xx11) 280-9198/3064-3567 - E-mail: gbusatto@ mtecnetsp.com.br 